\title{
Peer problems mediate the relationship between developmental coordination disorder and behavioral problems in school-aged children
}

\author{
Matthias Oliver Wagner ${ }^{\mathrm{a}, *}$, Klaus Bös ${ }^{\mathrm{b}}$, Julia Jascenoka ${ }^{\mathrm{c}}$, Darko Jekauc ${ }^{\mathrm{a}}$, Franz Petermann ${ }^{\mathrm{c}}$

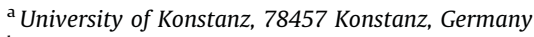 \\ ${ }^{\mathrm{b}}$ Institute for Sports and Sports Science, Karlsruhe Institute of Technology, 76131 Karlsruhe, Germany \\ ${ }^{\mathrm{c}}$ Centre for Clinical Psychology and Rehabilitation, University of Bremen, 28359 Bremen, Germany
}

Keywords:

Peer problems

Developmental coordination disorder

Behavioral problems

School-aged children

\begin{abstract}
A B S T R A C T
The aim of this study was to gain insights into the relationship between developmental coordination disorder, peer problems, and behavioral problems in school aged children where both internalizing and externalizing behavioral problems were considered. We assumed that the relationship between developmental coordination disorder and internalizing/externalizing problems in school aged children is mediated by peer problems and tested the hypothesis that a greater degree of motor impairment causes a greater degree of peer problems and thus a greater degree of internalizing or externalizing problems. Seventy boys and girls aged between 5 and 11 years were examined using the Movement Assessment Battery for Children 2 and the Intelligence and Developmental Scales. The results of path analysis showed that the relationship between developmental coordination disorder and internalizing/externalizing problems in school aged children is mediated at least in part by peer problems. However, the cross sectional design of the study does not provide conclusive evidence for a cause effect relationship and only allows for the conservative prognosis that a greater degree of motor impairment may cause a greater degree of peer problems and thus a greater degree of internalizing/ externalizing problems. Nevertheless, the results of this study emphasize the importance of being well integrated in their peer group especially for children with developmental coordination disorder.
\end{abstract}

\section{Introduction}

The child's development depends on the interaction of different functional areas, which can be described by motor, psychological, cognitive, perceptual, linguistic, and social aspects. The particular importance of well developed motor functions is already evident in early childhood. For instance, the ability to crawl and walk is not only important for the development of other functional skills such as running, hopping, and climbing, but also can positively affect a child's social and cognitive development (Piek, 2006, p. 145). If "Performance in daily activities that require motor coordination is substantially below that expected given the person's chronological age and measured intelligence," the presence of developmental coordination disorder (DCD) is possible (DSM IV TR 315.4 A; American Psychiatric Association, APA, 2000, p. 58). However, a final diagnosis of DCD should only be made when the detected performance problems interfere with academic achievements or daily activities and are not due to a general medical condition. Further, "If Mental Retardation is present, the motor difficulties are in excess of those usually associated with it." (see DSM IV TR 315.4 B D; APA, 2000, p. 58).

\footnotetext{
* Corresponding author.

E-mail address: matthias.wagner@uni-konstanz.de (M.O. Wagner).
} 
According to Magãlhaes, Cardoso, and Missiuna (2011) the most frequently cited motor issues in children with DCD are poor handwriting skills, difficulties in playing ball games and getting dressed.

DCD does not describe a single entity but should rather be understood as a collective term for a variety of different subtypes (Visser, 2003). Especially children with generalized sensorimotor deficits often show comorbid disorders such as attention deficit/hyperactivity disorder (ADHD; Gillberg \& Kadesjö, 2000) or reading disability (Kaplan, Wilson, Dewey, \& Crawford, 1998). Hence, the statement by Gilger and Kaplan (2001, p. 465) that in the field of developmental disabilities " [...] comorbidity [...] is the rule rather than the exception" obviously also applies to the field of DCD. Selected theories on comorbidity promise a better understanding of the nature, etiology (recently Moruzzi et al., 2010 versus Loh, Piek, \& Barrett, 2011) and the prognosis of DCD (see Visser, 2003). However, to facilitate a comprehensive developmental prognosis and to design effective interventions for children with DCD, it is especially relevant to understand how motor and non motor problems influence each other in a child's development (e.g., Kastner, Lipsius, Hecking, Petermann, Petermann, Mayer \& Springer (2011)Wagner, Kastner, Petermann, Worth, \& Bös, 2011) and to identify contextual characteristics that are important for this relation.

Green, Baird, and Sugden (2006) conclude that children diagnosed with DCD generally face emotional and behavioral problems. More specifically, the findings by Dewey, Kaplan, Crawford, and Wilson (2002) indicate that children with DCD show a greater degree of internalizing and externalizing problems compared to typically developing children. Both internalizing and externalizing problems can be considered as subgroups of emotional or behavioral problems. Internalizing behaviors are best characterized as inward directed, while externalizing behaviors manifest themselves as outward directed. Indications of internalizing behaviors include a child being depressed or having unfounded fears and phobias or excessive worries. Externalizing behaviors include a child violating societal norms or rules, ignoring teachers' reprimands or being hyperactive (Smith, 2007). The relation between DCD and the different aspects of internalizing and externalizing problems has been studied extensively in the literature. The most significant findings are that DCD is related with higher levels of anxiety (e.g., Pratt \& Hill, 2011), depression (e.g., Piek, Bradbury, Elsley, \& Tate, 2008) and introversion (e.g., Schoemaker \& Kalverboer, 1994) as well as ADHD (e.g., Rasmussen \& Gillberg, 2000) and the expression of deviant behaviors (e.g., Kanioglou, Tsorbatzoudis, \& Barkoukis, 2005).

In addition to problems in psychosocial adjustment, children with DCD may be at risk for peer relationship problems (Dewey et al., 2002). For instance, children with DCD often spend their recess alone (Bouffard, Watkinson, Thompson, Causgrove Dunn, \& Romanow, 1996), generally choose more quiet activities (Jarus, Lourie Gelberg, Engel Yeger, \& Bart, 2011), show a low engagement in social physical play (Smyth \& Anderson, 2000) or organized sports (Magãlhaes et al., 2011) and perceive less enjoyment in daily activities (Bart, Jarus, Erez, \& Rosenberg, 2011) as well as less social support (Skinner \& Piek, 2001). Especially boys diagnosed with DCD tend to show a low engagement in moderate to vigorous (Green et al., 2011) as well as structured and unstructured (Poulsen, Ziviani, Cuskelly, \& Smith, 2007) group physical activities. These findings support the general impression of a poor socialization (Kanioglou et al., 2005) or even social isolation (Smyth \& Anderson, 2000) in children with DCD; a phenomenon that appears to remain stable throughout adolescence (Cantell, Smyth, \& Ahonen, 1994).

In addition, the meta analysis by Reijntjes, Kamphuis, Prinzie, and Telch (2010), the randomized controlled intervention study by Witvliet, van Lier, Cuijpers, and Koot (2009) and the short term prospective investigation by Schwartz, McFayden Ketchum, Dodge, Pettit, and Bates (1998) support the idea that peer problems and internalizing/externalizing problems are closely related.

However, to date the complex relationship between DCD, peer problems and internalizing or externalizing problems is largely unknown. A better understanding of this relationship is important for a more comprehensive developmental prognosis and the development of effective interventions for children with DCD.

The aim of this study was to gain insights into the relationship between DCD, peer problems, and behavioral problems in school aged children. Both internalizing and externalizing behavioral problems were considered because of their potential co development and uni directional (in girls)/bi directional (in boys) progression shown in a four year cross lagged panel study by Lee and Bukowski (2012).

Based on the assumption that development results of a dynamic and action mediated person environment interaction (see also Lerner, 1998) and considering the results of the literature, we assumed that the relationship between DCD and internalizing/externalizing problems in school aged children is mediated by peer problems. We hypothesized that a greater degree of motor impairment causes a greater degree of peer problems and thus a greater degree of internalizing and externalizing problems.

\section{Materials and methods}

\subsection{Sample}

Thirty five children who underwent occupational therapy ${ }^{1}$ (occupational therapy group, OTG; for demographic information see Table 1) and 35 typically developed children matched for age and gender (control group, CG) were included in this cross sectional study.

\footnotetext{
${ }^{1}$ At the time of the investigation, the children had received a maximum of five 50 -min therapy sessions, where each therapist using their own individual approach.
} 
Table 1

Demographic information on the occupational therapy group.

\begin{tabular}{lccr}
\hline & Total & Boys & Girls \\
\hline Mean age & 7.69 & 7.52 & 8.25 \\
SD & 1.55 & 1.65 & 1.04 \\
Min & 5.00 & 5.00 & 7.00 \\
Max & 11.00 & 11.00 & 10.00 \\
$N$ & 35 & 27 & 8 \\
\hline
\end{tabular}

Table 2

Average percentile ranks of the Movement-ABC motor test in the occupational therapy group.

\begin{tabular}{lccc}
\hline & Total & Boys & Girls \\
\hline Mean & 4.77 & 4.68 & 5.05 \\
SD & 4.94 & 5.33 & 3.67 \\
Min & 0.10 & 0.10 & 0.40 \\
Max & 16.00 & 16.00 & 9.00 \\
$N$ & 34 & 26 & 8 \\
\hline
\end{tabular}

Participants were recruited from selected occupational therapy practices and elementary schools. The Movement Assessment Battery for Children 2 (Movement ABC 2; Henderson, Sugden, \& Barnett, 2007; Petermann, 2011) was used to determine children's degree of motor impairment in both groups (for a more detailed description of the test procedure, see Section 2.2). The resulting Movement ABC 2 raw scores were transferred into corresponding percentile ranks on the basis of German normative data (Petermann, 2011). Table 2 shows the average percentile ranks (PR) in the occupational therapy group.

The average PR clearly showed that boys and girls in the occupational therapy group met the criteria of a significant motor impairment $(P R<5)$ or should at least be carefully monitored (PR 6 15). In other words, these children "[...] fell substantially below performance expected given their chronological age [...]" (DSM IV TR 315.4 A; APA, 2000, p. 58). OTG Children's motor impairment "[...] significantly interfered with their academic achievement or activities of daily living." (DSM IV TR 315.4 B; APA, 2000, p. 58), was " [...] not due to a general medical condition (e.g., cerebral palsy, hemiplegia, or muscular dystrophy) and [did] not meet criteria for a Pervasive Developmental Disorder." (DSM IV TR 315.4 C; APA, 2000 , p. 58). A total of 21 children were excluded prior to the investigation due to poor cognitive performances (nonverbal IQ $<70$; ICD 10 F 82.0 D; WHO, 2005), wherefore DSM IV TR 315.4 D was not considered.

\subsection{Measurements}

The German version (Petermann, 2011) of the Movement Assessment Battery for Children 2 (Movement ABC 2; age band 1 3; Henderson et al., 2007) was used to determine children's degree of motor impairment. Measurements for eight subtests assigned to the three dimensions 'manual dexterity' (MD), 'aiming and catching' (AC) and 'balance' (BL) were recorded and summed to a Total Score (TS). The supplementary parents questionnaire of the Intelligence and Developmental Scales (IDS, ${ }^{2}$ Grob, Meyer, \& Hagmann von Arx, 2009) was used to determine children's degree of peer problems and their degree of internalizing and externalizing problems (see also Kastner \& Petermann, 2010). An example for each subscale is shown in Fig. 1.

The subscales for peer problems (four items, $\alpha=0.931$ ) and for internalizing (six items, $\alpha=0.809$ ) and externalizing (seven items, $\alpha=0.895$ ) problems were defined based on the factor analytical considerations by Kastner (2010). The high internal consistency of the Peer Problem Subscale allows for the formation of a Peer Problem (Subscale) Score (PPS = sum of item scores/number of items; [0 4]). Similarly, subscale scores for internalizing (IPS; [0 4]) and externalizing (EPS; [0 4]) problems were formed. The Total Score (TS; [ $\left.\begin{array}{ll}0 & 15\end{array}\right]$ ) was computed according to the Movement ABC 2 manual (see Henderson et al., 2007, p. 82). Higher (subscale) scores represent a greater degree of motor impairment, peer problems and internalizing/externalizing problems.

\subsection{Procedure}

All parents received detailed information about the research project either in written form or orally (in the form of a parent's evening). The written consent of the parents was obtained before the start of the test procedures with the option to revoke their consent at any time. The motor testing was conducted as a single test in selected practices and schools. The questionnaire was usually completed by the accompanying mother in a separate room at the same time their children were

\footnotetext{
${ }^{2}$ The IDS is a general developmental test with an integrated intelligence test and represents a revision of the Kramer-Intelligence Test that can be used in $5 ; 00$ to $10 ; 11$ year-old children.
} 


\begin{tabular}{|c|c|c|c|c|c|}
\hline \multicolumn{6}{|c|}{ Please tick the most appropriate answer: } \\
\hline & $\mathbf{0}$ & 1 & 2 & 3 & 4 \\
\hline a Has many friends & $\not$ & a & a & Q & a \\
\hline${ }^{\mathrm{b}}$ Is anxious, worried & 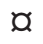 & a & 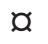 & a & a \\
\hline${ }^{\mathrm{C}}$ Is overly aggressive with peers & a & , & a & a & a \\
\hline
\end{tabular}

Fig. 1. Exemplary items from the subscales on: (a) peer problems, (b) internalizing problems, and (c) externalizing problems used in the Intelligence and Developmental Scales.

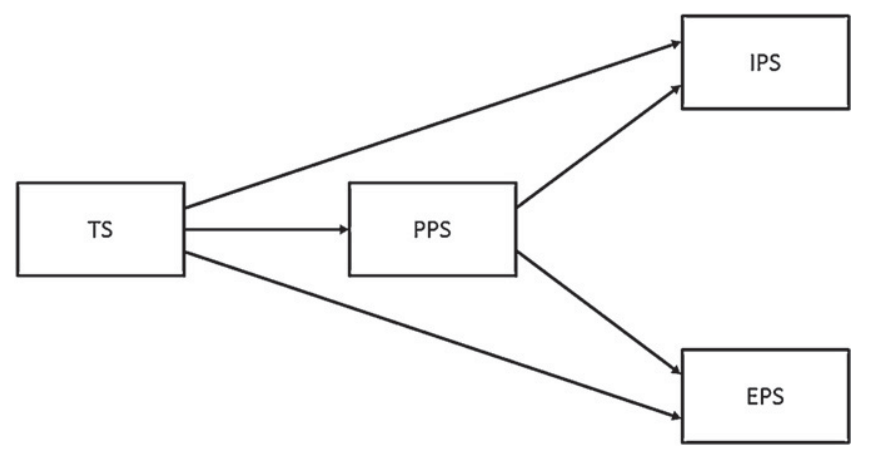

Fig. 2. Path diagram showing the relationship between the Total Score (TS), the Peer Problem Score (PPS), the Internalizing Problem Score (IPS), and the Externalizing Problem Score (EPS).

tested. In appreciation of their participation, participants could request a personal conversation where they received their test results.

\subsection{Data analysis}

Testing the postulated mediations between motor impairment, peer problems, and internalizing/externalizing problems simultaneously using the respective total scores is a multivariate problem; the corresponding path diagram is shown in Fig. 2.

According to the hypothesis, all model paths between the exogenous (TS) and endogenous (PPS, IPS, EPS) variables and between the endogenous variables are directed. Therefore, one tailed testing was performed, and the error probability was set a priori to $\alpha=0.05$.

Full information maximum likelihood (FIML) estimation was performed using AMOS (Arbuckle, 2006) Version 20 (IBM, Armonk, NY). Assuming multivariate normal distribution of the data and that data are missing at random or completely at random, FIML provides unbiased parameter estimates (Enders \& Bandalos, 2001). ${ }^{3}$ The proportion of missing data for each variable in the model ranged from $2.9 \%$ to $10.0 \%$. The overall proportion of missing data was $5.7 \%$ ( 16 of 280 responses). MCAR Test by Little (1988) was not significant $\left(\chi^{2}=6.90 ; d f=13 ; p=0.907\right)$ indicating that the missingness was not systematic. Moreover, no striking pattern could be found within the missing data.

To evaluate the model fit, selected incremental fit indices were referenced including Root Mean Square Error of Approximation (RMSEA) and Comparative Fit Index (CFI). The indices were selected according to Beauducel and Wittmann (2005) and evaluated based on the recommendations of Hu and Bentler (1999).

\section{Results}

\subsection{Descriptive measures}

The results presented in Table 3 showed that the children in the occupational therapy group had consistently higher scores than those in the control group, which indicates a greater degree of motor impairment and a greater degree of peer, internalizing and externalizing problems.

\footnotetext{
${ }^{3}$ Even when the assumption of multivariate normality is violated, FIML provides relatively good estimations compared to deletion or mean imputation methods (Enders \& Bandalos, 2001).
} 
Table 3

Descriptive measures of the Movement-ABC Total Score and the Intelligence and Developmental Scales (subscale) scores for the two sample groups and the entire study sample.

\begin{tabular}{|c|c|c|c|c|c|c|c|c|c|c|c|c|}
\hline & \multicolumn{3}{|l|}{$\mathrm{TS}^{\mathrm{a}}$} & \multicolumn{3}{|l|}{ PPS $^{\mathrm{b}}$} & \multicolumn{3}{|l|}{$\mathrm{IPS}^{\mathrm{c}}$} & \multicolumn{3}{|l|}{$\mathrm{EPS}^{\mathrm{d}}$} \\
\hline & $\mathrm{OTG}^{\mathrm{e}}$ & $\mathrm{CG}^{\mathrm{f}}$ & Total & $\mathrm{OTG}^{\mathrm{e}}$ & $\mathrm{CG}^{\mathrm{f}}$ & Total & $\mathrm{OTG}^{\mathrm{e}}$ & $\mathrm{CG}^{\mathrm{f}}$ & Total & $\mathrm{OTG}^{\mathrm{e}}$ & $\mathrm{CG}^{\mathrm{f}}$ & Total \\
\hline Mean & 10.77 & 4.79 & 7.78 & 1.67 & 1.08 & 1.37 & 1.03 & 0.50 & 0.76 & 1.23 & 0.53 & 0.87 \\
\hline SD & 1.79 & 2.36 & 3.66 & 1.09 & 0.95 & 1.06 & 0.62 & 0.61 & 0.67 & 0.91 & 0.61 & 0.84 \\
\hline Min & 8.00 & 0.00 & 0.00 & 0.00 & 0.00 & 0.00 & 0.17 & 0.00 & 0.00 & 0.00 & 0.00 & 0.00 \\
\hline Max & 14.00 & 11.00 & 14.00 & 3.50 & 3.75 & 3.75 & 3.17 & 2.50 & 3.17 & 3.00 & 2.57 & 3.00 \\
\hline Skew & 0.18 & 0.38 & -0.16 & 0.23 & 1.09 & 0.62 & 1.25 & 1.68 & 1.13 & 0.39 & 1.88 & 0.98 \\
\hline Kurt & -1.08 & 0.32 & -1.03 & -1.05 & 0.68 & -0.66 & 3.08 & 2.86 & 1.63 & -0.61 & 3.63 & 0.11 \\
\hline$N$ & 34 & 34 & 68 & 33 & 34 & 67 & 32 & 34 & 66 & 31 & 32 & 63 \\
\hline
\end{tabular}

Total Score.

b Peer Problem Score.

c Internalizing Problem Score.

d Externalizing Problem Score.

e Occupational therapy group.

f Control group.

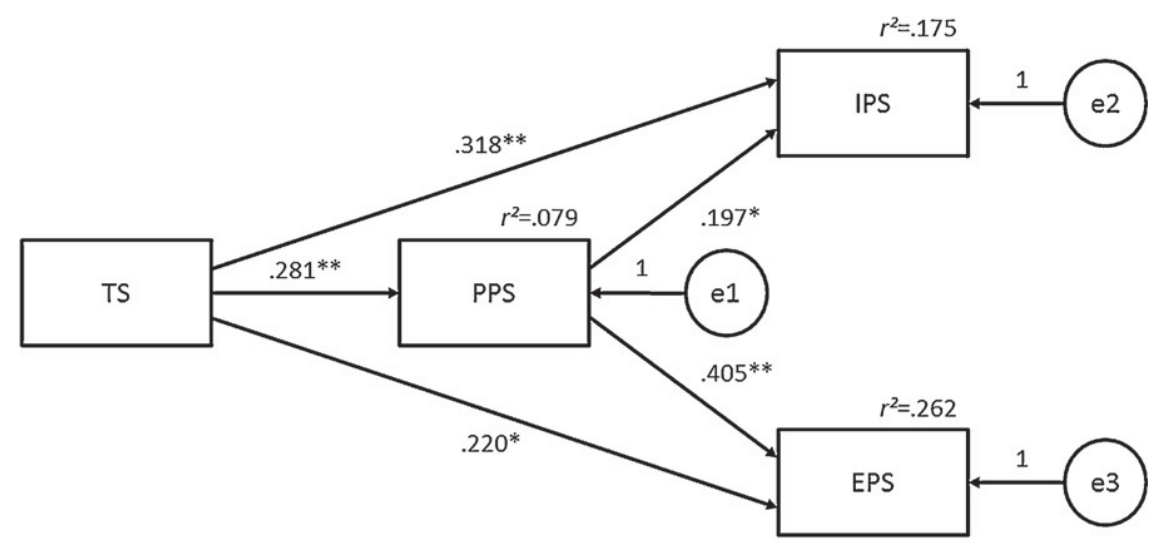

chi-square $=0.530 ; d f=1 ; p=.467 ;$ RMSEA $=0.000[0.000-0.284] ; C F I=1.000$

Fig. 3. Results of the path analysis (Standardized Regression Weights). TS, Total Score; PPS, Peer Problem Score; IPS, Internalizing Problem Score; EPS, Externalizing Problem Score; e1-e3, error variables; $r^{2}$, Squared Multiple Correlations; $d f$, degrees of freedom; $p$, probability level; * $p<0.05$; ${ }^{* *} p<0.01$; RMSEA, Root-Mean-Square-Error of Approximation; CFI, Comparative-Fit-Index.

\subsection{Hypothesis testing}

The results of the path analysis are shown in Fig. 3. The $\chi^{2}$ statistic revealed no significant differences between the theoretical and the empirical covariance matrix $\left(\chi^{2}=0.530 ; d f=1 ; p=0.467\right)$. The incremental fit indices (RMSEA $=0.000$ [0.000; 0.284]; CFI =1.000) were below the upper limit of RMSEA $(<0.08)$ and above the lower limit of CFI $(>0.95)$.

The following direct and indirect effects were observed:

(i) The greater the degree of motor impairment, (a) the greater the degree of peer problems $(\beta=0.281 ; p<0.01)$ and (b) the greater the degree of internalizing $(\beta=0.318 ; p<0.01)$ and externalizing $(\beta=0.220 ; p<0.05)$ problems in school aged children.

(ii) The greater the degree of peer problems, the greater the degree of internalizing $(\beta=0.197 ; p<0.05)$ and externalizing $(\beta=0.405 ; p<0.01)$ problems in school aged children.

Hence, the relationship between DCD and internalizing/externalizing problems in school aged children was mediated by peer problems. However, the significant direct paths between motor impairment and internalizing/externalizing problems contradict the assumption of a complete mediation.

\section{Discussion}

The aim of this study was to gain insights into the relationship between DCD, peer problems, and behavioral problems in school aged children where both internalizing and externalizing behavioral problems were considered. The results of this 
study suggest that the relationship between DCD and internalizing/externalizing problems in school aged children is indeed mediated at least in part by peer problems. In addition, the signs of the path weights indicate that a greater degree of motor impairment causes a greater degree of peer problems and thus a greater degree of internalizing/externalizing problems.

Based on the results of this study, the question arises why children with DCD often have problems in getting along with their peers. One essential prerequisite for social interaction and the development of socially desirable behaviors is the ability for empathy (Thompson, 1987). The development of empathic abilities in turn requires the ability to perceive visual stimuli in an interpersonal context (Lemerise \& Arsenio, 2000). Especially children with DCD often show difficulties in recognizing emotional stimuli in the facial expression of their peers (Cummins, Piek, \& Dyck, 2005). Thus, they often tend to show an inadequate amount of empathy (Kastner \& Petermann, 2010), which is one possible explanation for the deficits in peer relationships shown by Dewey et al. (2002). Therefore, visual perceptual skills (see also Tsai, Wilson, \& Wu, 2008) presumably mediate the relationship between motor skills and those emphatic skills that are relevant for the development and maintenance of positive peer relationships (see also Kastner \& Petermann, 2010).

Further, the relationship between peer problems and internalizing/externalizing problems may be interceded by mediating variables. For instance, Skinner and Piek (2001) reported lower self worth in children with DCD. Including self worth is relevant because (i) the relationship between peer problems and internalizing symptoms is mediated (in girls) or moderated (in boys) by a negative self worth (cf. Grills \& Ollendick, 2002), and (ii) internalizing problems can be assumed in a self concept mediated, reciprocal deterministic relationship with externalizing behavior problems (Lee \& Stone, 2012).

Interestingly, DCD influenced peer problems are more strongly related to externalizing than to internalizing problems. This results can be explained assuming a reciprocal deterministic relationship between behavior and self concept (Lee \& Stone, 2012) or between self perception and peer relationships (Salmivalli \& Isaacs, 2005), respectively. Although neither internalizing (see Reijntjes et al., 2010) nor (for boys) externalizing (cf. Kochenderfer \& Ladd, 1997) reactions promise a reduction of victimization and exclusion, children with externalizing disorders appear to be more interested in bonding with deviant peers (Patterson, Forgatch, Yoerger, \& Stoolmiller, 1998; Rasmussen \& Gillberg, 2000). Bad company prospectively reinforces children's own deviant behavior, which is a possible explanation for the relatively stronger mediation found in the present study. However, because the prevalence of externalizing behaviors is generally higher in boys than in girls (recently Yang, Li, Zhang, Tein, \& Liu, 2008) the difference in the strength between the two mediations could also be explained by the overrepresentation of boys in the study. In any case, the stronger mediation between motor impairment, peer problems, and externalizing problems serves as a statistical explanation for the relatively stronger significant direct effect of motor impairment on internalizing than on externalizing problems. However, it is possible that both direct effects would decrease with the inclusion of the aforementioned mediators.

The limitations of this study include its cross sectional design that does not allow for identifying the cause effect relationship between motor impairment, peer problems, and internalizing/externalizing problems. Other limitations of this study are the wide age range, the unequal distribution of genders, the heterogeneous number of treatments and the different therapy approaches used in the occupational therapy group. Concerning measurement instruments, it has to be questioned whether the Movement $A B C 2$ actually provides a valid diagnosis of motor impairment (recently Schulz, Henderson, Sugden, \& Barnett, 2011, Wagner, Kastner, Petermann, \& Bös, 2011). A corresponding compendium for early diagnosis of motor functions has been published recently (see Wagner, Macha, et al., 2011). Finally, the measurement of peer and behavioral problems should be discussed more critically: although the psychometric properties of the IDS appear quite strong, the findings of this study should be confirmed in future studies using more standardized measurements such as, for instance, the Juvenile Victimization Questionnaire (JVQ; Finkelhor, Hamby, Ormrod, \& Turner, 2005) and the Strength and Difficulties Questionnaire (SDQ; Goodman, 1997).

In summary, the assumed direction of the paths should be further investigated in longitudinal studies with an age and gender homogenous sample after receiving a comparable number of similar OT treatments. Therefore, the discussion on other intrapersonal (e.g., visual perception, emotional recognition, self worth) and contextual (e.g., parents, teachers) mediators (including their reciprocal dependencies) and moderators (e.g., gender) has to be continued as well as the discussion on valid measurements for the different constructs.

In expansion of the findings of Dewey et al. (2002), the results of the current study showed that the relationship between DCD and internalizing/externalizing problems in school aged children is mediated at least in part by peer problems. In regard to a more comprehensive developmental prognosis for children with DCD it can be assumed with caution that a greater degree of motor impairment may cause a greater degree of peer problems and thus a greater degree of internalizing/ externalizing problems.

Our findings suggest that integration into the peer group is particularly important for achieving a permanent reduction of psychosocial behavioral problems in children with DCD. However, integration into the peer group not only depends on the improvement of motor skills using tasks oriented approaches with cognitive elements (for an overview see Polatajko \& Cantin, 2006), but also can also under the assumption of reciprocal determinism result from appropriate behavioral interventions (see overview in Weisz, Hawley, \& Jensen Doss, 2004). The success and sustainability of such combined measures presumably depend on how parents, teachers, and friends succeed in enhancing empathy, cooperation and self worth of the affected children. The ability to consider the feelings of others, accept rules and standards and focus on one's own strengths and weaknesses improves a child's prospect to permanently establish themselves in their peer group. Positive and stable peer relationships can be seen as the basis for an increased participation in physical/sports activities (for the effect of in deficit peer relationships on physical activity patterns see Storch, Milsom, DeBraganza, Lewin, Geffken \& Silverstein, 
2007). Resulting increase of movement and socialization experiences presumably initiates and supports the self regulatory process against establishment of complex motor and psychosocial behavioral problems.

\section{Conclusion}

The relationship between DCD and internalizing/externalizing problems in school aged children is mediated at least in part by peer problems. A greater degree of motor impairment may cause a greater degree of peer problems and thus a greater degree of internalizing or externalizing problems.

\section{Disclosure statement}

The authors declare that there is no actual or potential conflict of interest.

\section{Acknowledgments}

The authors would like to thank Priv. Doz. Dr. Annegret Mündermann (ABR Solutions) who provided scientific writing services on behalf of the authors. Furthermore, the authors would like to thank Prof. Dr. Hans Christian Waldmann (University of Bremen) and Prof. Dr. Sonja Perren (Jacobs Center for Productive Youth Development, Zurich) for productive and collegial discussions.

\section{References}

American Psychiatric Association. (2000). Diagnostic and statistical manual of mental disorders (4th ed., text rev.). Washington, DC: Author.

Arbuckle, J. L. (2006). Amos (Version 7.0) [Computer Program]. Chicago: SPSS.

Bart, O., Jarus, T., Erez, Y., \& Rosenberg, L. (2011). How do young children with DCD participate and enjoy daily activities? Research in Developmental Disabilities, 32, $1317-1322$.

Beauducel, A., \& Wittmann, W. W. (2005). Simulation study on fit indices in confirmatory factor analysis based on data with slightly distorted simple structure. Structural Equation Modeling, 12, 41-75.

Bouffard, M., Watkinson, E., Thompson, L., Causgrove Dunn, J., \& Romanow, S. (1996). A test of the activity deficit hypothesis in children with movement difficulties. Adapted Physical Activity Quarterly, 13, 61-73.

Cantell, M., Smyth, M., \& Ahonen, T. (1994). Clumsiness in adolescence: Educational, motor and social outcomes of motor delay detected at 5 years. Adapted Physical Activity Quarterly, 11, 115-129.

Cummins, A., Piek, J. P., \& Dyck, M. (2005). Motor coordination, empathy, and social behaviour in school-aged children. Developmental Medicine and Child Neurology, 47, 437-442.

Dewey, D., Kaplan, B. J., Crawford, S. G., \& Wilson, B. N. (2002). Developmental coordination disorder: Associated problems in attention, learning, and psychosocial adjustment. Human Movement Science, 21, 905-918.

Enders, C. K., \& Bandalos, D. L. (2001). The relative performance of full information maximum likelihood estimation for missing data in structural equation models. Structural Equation Modeling, 8, 430-457.

Finkelhor, D., Hamby, S. L., Ormrod, R., \& Turner, H. (2005). The Juvenile Victimization Questionnaire: Reliability, validity, and national norms. Child Abuse and Neglect, 29, 383-412.

Gilger, J. W., \& Kaplan, B. J. (2001). Atypical brain development: A conceptual framework for understanding developmental learning disabilities. Developmental Neuropsychology, 20, 465-481.

Gillberg, C., \& Kadesjö, B. (2000). Attention-deficit/hyperactivity disorder and developmental coordination disorder. In T. E. Brown (Ed.), Attention-deficit disorders and comorbidities in children, adolescents, and adults (pp. 393-406). Washington: American Psychiatric Publishing.

Goodman, R. (1997). The strengths and difficulties questionnaire: A research note. Journal of Child Psychology and Psychiatry, 38, 581-586.

Green, D., Baird, G., \& Sugden, D. (2006). A pilot study of psychopathology in developmental coordination disorder. Child Care Health Development, 32, 741-750.

Green, D., Lingham, R., Mattocks, C., Riddoch, C., Ness, A., \& Emond, A. (2011). The risk of reduced physical activity in children with probable developmental coordination disorder: A prospective longitudinal study. Research in Developmental Disabilities, 32, 1323-1342.

Grills, A. E., \& Ollendick, T. H. (2002). Peer victimization, global self-worth, and anxiety in middle school children. Journal of Clinical Child and Adolescent Psychology, 31, 59-68.

Grob, A., Meyer, C. S., \& Hagmann-von Arx, P. (2009). Intelligence and Development Scales (IDS). [Intelligenz- und Entwicklungsskalen für Kinder von 5-10 Jahren]. Bern: Huber.

Henderson, S. E., Sugden, D. A., \& Barnett, A. L. (2007). Movement Assessment Battery for Children - Second edition (Movement ABC-2). London: Harcourt Assessment.

Hu, L., \& Bentler, P. M. (1999). Cutoff criteria for fit indexes in covariance structure analysis: Conventional criteria versus new alternatives. Structural Equation Modeling, 6, 1-55.

Jarus, T., Lourie-Gelberg, Y., Engel-Yeger, B., \& Bart, O. (2011). Participation patterns of school-aged children with and without DCD. Research in Developmental Disabilities, 32, 1323-1331.

Kanioglou, A., Tsorbatzoudis, H., \& Barkoukis, V. (2005). Socialization and behavioural problems of elementary school pupils with developmental coordination disorder. Perceptual and Motor Skills, 101, 163-173.

Kaplan, B. J., Wilson, B. N., Dewey, D., \& Crawford, S. G. (1998). DCD may not be a discrete disorder. Human Movement Science, 17, 471-490.

Kastner, J. (2010). Entwicklungsbedingte Koordinationsstörungen: Eine Kohorten-Vergleichsstudie zum Ausmaß kognitiver und psychosozialer Beeinträchtigungen. Dissertation. Universität Bremen.

Kastner, J., \& Petermann, F. (2010). Entwicklungsbedingte Koordinationsstörungen: Zur Bedeutung kognitiver Beeinträchtigungen im Zusammenhang motorischkoordinativer Defizite und psychischer Verhaltensauffälligkeiten [Developmental coordination disorder: The importance of cognitive impairments in the relationship between movement deficits and psychological problems]. Zeitschrift für Sportpsychologie, 17, 36-49.

Kastner, J., Lipsius, M., Hecking, M., Petermann, F., Petermann, U., Mayer, H., \& Springer, S. (2011). Kognitive Leistungsprofile motorisch- und sprechentwicklungsverzögerter Vorschulkinder (Cognitive profiles of preschool children with developmental coordination disorders and developmental language disorders). Kindheit and Entwichlung, 20, 173-185.

Kochenderfer, B. J., \& Ladd, G. W. (1997). Victimized children's responses to peers' aggression: Behaviors associated with reduced versus continued victimization. Development and Psychopathology, 9, 59-73.

Lee, E. J., \& Bukowski, W. M. (2012). Co-development of internalizing and externalizing problem behaviors: Causal direction and common vulnerability. Journal of adolescence, 35, 713-729. 
Lee, E. J., \& Stone, S. I. (2012). Co-occurring internalizing and externalizing behavioral problems: The mediating effect of negative self-concept. Journal of Youth and Adolescence, 41, 717-731.

Lemerise, A., \& Arsenio, W. (2000). An integrated model of emotion progress and cognition in social information processing. Child Development, 71, 107-118.

Lerner, R. M. (1998). Theories of human development: Contemporary perspectives. In R. M. Lerner (Ed.), Handbook of child development. Vol. 1: Theoretical models of human development. New York: Wiley \& Sons.

Little, R. J. A. (1988). A test of missing completely at random for multivariate data with missing values. Journal of the American Statistical Association, 83, 1198-1202.

Loh, P. R., Piek, J. P., \& Barrett, N. C. (2011). Comorbid ADHD and DCD: Examining cognitive functions using the WISC-IV. Research in Developmental Disabilities, 32 $1260-1269$.

Magãlhaes, L. C., Cardoso, A. A., \& Missiuna, C. (2011). Activities and participation in children with developmental coordination disorder: A systematic review. Research in Developmental Disabilities, 32, 1309-1316.

Moruzzi, S., Pesenti-Gritti, P., Brescianini, S., Salemi, M., Battaglia, M., \& Ogliari, A. (2010). Clumsiness and psychopathology: Causation or shared etiology? A twin study with the CBCL 6-18 questionnaire in a general school-age population sample. Human Movement Science, 29, 326-338.

Patterson, G. R., Forgatch, M. S., Yoerger, K. L., \& Stoolmiller, M. (1998). Variables that initiate and maintain an early-onset trajectory for juvenile offending. Development and Psychopathology, 10, 531-547.

Petermann, F. (Ed.). (2011). Movement Assessment Battery for Children-2 (M-ABC-2) (3rd rev.). Frankfurt: Pearson Assessment.

Piek, J. P. (2006). Infant motor development. Champaign, IL: Human Kinetics.

Piek, J. P., Bradbury, G. S., Elsley, S. C., \& Tate, L. (2008). Motor coordination and social-emotional behaviour in preschool-aged children. International Journal of Disability, Development and Education, 55, 143-151.

Polatajko, H. J., \& Cantin, N. (2006). Developmental coordination disorder (Dyspraxia): An overview of the state of the art. Seminars in Pediatric Neurology, 12, 250258.

Poulsen, A. A., Ziviani, J. M., Cuskelly, M., \& Smith, R. (2007). Boys with developmental coordination disorder: Loneliness and team sports participation. The American Journal of Occupational Therapy, 61, 451-462.

Pratt, M. L., \& Hill, E. L. (2011). Anxiety profiles in children with and without developmental coordination disorder. Research in Developmental Disabilities, 32, 12531259.

Rasmussen, P., \& Gillberg, C. (2000). The natural outcome of ADHD with DCD at 22 years. A controlled longitudinal community-based study of individuals first diagnosed at age 7 years. Journal of the American Academy of Child and Adolescent Psychiatry, 39, 1424-1431.

Reijntjes, A., Kamphuis, J. H., Prinzie, P., \& Telch, M. J. (2010). Peer victimization and internalizing problems in children: A meta-analysis of longitudinal studies. Child Abuse and Neglect, 34, 244-252.

Salmivalli, C., \& Isaacs, J. (2005). Prospective relations among victimization, rejection, friendlessness, and children's self- and peer-perceptions. Child Development, $76,1161-1171$

Schulz, J., Henderson, S. E., Sugden, D. A., \& Barnett, A. L. (2011). Structural validity of the Movement ABC-2 test: Factor structure comparisons across three age groups. Research in Developmental Disabilities, 32, 1361-1369.

Schoemaker, M., \& Kalverboer, A. F. (1994). Social and affective problems of children who are clumsy: How early do they begin? Adapted Physical Activity Quarterly, $11,130-140$.

Schwartz, D., McFayden-Ketchum, S. A., Dodge, K. A., Pettit, G. S., \& Bates, J. E. (1998). Peer group victimization as a predictor of children's behavior problems at home and in school. Development and Psychopathology, 10, 87-99.

Skinner, R., \& Piek, J. (2001). Psychosocial implications of poor motor coordination in children and adolescents. Human Movement Science, 20, 73-94.

Smith, D. D. (2007). Introduction to special education: Making a difference (6th edition). Boston: Allyn \& Bacon.

Smyth, M. M., \& Anderson, H. I. (2000). Coping with clumsiness in the school playground: Social and physical play in children with coordination impairments. British Journal of Developmental Psychology, 18, 389-413.

Storch, E. A., Milsom, V. A., DeBraganza, N., Lewin, A. B., Geffken, G. R., \& Silverstein, J. H. (2007). Peer victimization, psychosocial adjustment, and physical activity in overweight and at-risk-for-overweight youth. Journal of Pediatric Psychology, 32, 80-89.

Thompson, R. (Ed.). (1987). Empathy and emotional understanding: The early development of empathy. Cambridge: Cambridge University Press.

Tsai, C., Wilson, P., \& Wu, S. (2008). Role of visual-perceptual skills (non-motor) in children with developmental coordination disorder. Human Movement Science, 27, 649-664.

Visser, J. (2003). Developmental coordination disorder: A review of research on subtypes and comorbidities. Human Movement Science, $22,479-493$.

Wagner, M. O., Kastner, J., Petermann, F., \& Bös, K. (2011). Factorial validity of the Movement Assessment Battery for Children-2 (age band 2). Research in Developmental Disabilities, 32, 674-680.

Wagner, M. O., Kastner, J., Petermann, F., Worth, A., \& Bös, K. (2011). The impact of obesity on developmental coordination disorders in adolescence. Research in Developmental Disabilities, 32, 1970-1976.

Wagner, M. O., Macha, T., Kastner, J., Petermann, F., Jekauc, D., Worth, A., et al. (2011). Frühdiagnostik motorischer Funktionen [Early diagnosis of motor function]. Diagnostica, 57, 225-233.

Weisz, J. R., Hawley, K. M., \& Jensen Doss, A. (2004). Empirically tested psychotherapies for youth internalizing and externalizing problems and disorders. Child and Adolescent Psychiatric Clinics of North America, 13, 729-815.

WHO (Hrsg.). (2005). Internationale Klassifikation psychischer Störungen - ICD-10, Kapitel V (F). Klinisch-diagnostische Leitlinien (4. Aufl.). Bern: Huber

Witvliet, M., van Lier, P. A. C., Cuijpers, P., \& Koot, H. M. (2009). Testing links between childhood positive peer relations and externalizing outcomes through a randomized controlled intervention study. Journal of Consulting and Clinical Psychology, 77, 905-915.

Yang, Y., Li, H., Zhang, Y., Tein, J.-Y., \& Liu, X. (2008). Age and gender differences in behavioral problems in Chinese children: Parent and teacher reports. Asian Journal of Psychiatry, 1, 42-46. 